\title{
Apresentação: gênero no mercado do sexo
}

\author{
Mercado. [do latim mercatu] S. m. \\ 3. Permutação ou troca de produtos e valores; 0 comércio \\ 4. Econ A relação estabelecida entre a oferta e a procura \\ de bens e/ou serviços e/ou capitais ${ }^{1}$
}

Pensar nas marcas de gênero que atravessam o mercado do sexo é um desafio que remete a diversas ordens de questões. Antes de explorá-las, contudo, uma observação é necessária. Porque utilizar essa expressão, mercado do sexo, e não outra (prostituição, por exemplo)?

O sexo comercial tem dado lugar a uma verdadeira indústria. Laura Agustín afirma que considerar os elementos que a integram conduz a perceber que nos deparamos não com "a prostituição", mas com uma diversidade de trabalhos sexuais. E a lista é imensa, abarcando os desempenhados em bordéis, boates, bares, discos, saunas, linhas telefônicas eróticas, sexo virtual através da Internet, casas de massagem, serviços de acompanhantes, agências matrimoniais, hotéis, motéis, cinemas e revistas pornôs, filmes e vídeos, serviços de dominação e submissão/sado-masoquismo, prostituição na rua. Segundo a autora, para além de ocultar essa diversidade, o termo prostituição também pode obscurecer a compreensão de há, de fato, um mercado, e, portanto, desviar a atenção da demanda, dos diversos desejos das pessoas que procuram serviços sexuais. ${ }^{2}$

\footnotetext{
${ }^{1}$ Novo Dicionário Aurélio da Língua Portuguesa, 2aㅡ Ed., Rio de J aneiro, Editora Nova Fronteira, 1986.

${ }^{2}$ Agustín, Laura. Trabajar en la indústria del sexo, y otros tópicos migratórios. Tercera Prensa, Donosti, 2005.
} 
Gênero no mercado do sexo

Concordando com Agustín, adicionaria um terceiro ponto. As definições correntes da prostituição tampouco contribuem para pensar nos diversos tipos de inserção em um jogo de oferta e demanda de sexo e sensualidade que, marcado pela mercantilização, não necessariamente assume a forma de um contrato explícito de intercâmbio entre sexo e dinheiro. Em outras palavras, a inserção no mercado do sexo está longe de restringirse à realização do que, no Brasil, é popularmente conhecido como programas. Como exemplo cito a conhecida figura, no país, do "velho que ajuda" ${ }^{3}$, meio através do qual jovens das camadas populares, inclusive garotas que não são consideradas prostitutas, procuram apoio econômico e muitas das interações presentes nos universos do turismo à procura de sexo, em diversas partes do mundo, envolvendo viajantes (homens ou mulheres) dos países ricos em direção a regiões pobres. ${ }^{4}$ Os textos de Ana Paula da Silva e Thaddeus Blanchette e de Adriana Piscitelli, neste número, além de considerar seriamente noções e preferências de agentes situados, nesses universos, no lado da "demanda", indicam a clara percepção dos consumidores da amplidão de um mercado global do sexo que não se restringe à "prostituição".

\footnotetext{
${ }^{3}$ FonseCA, Cláudia: A morte de um gigolô. In: Piscitelli, A. et alii (orgs.) Sexualidade e Saberes, Convenções e Fronteiras. Rio de J aneiro, Garamond, 2004.

${ }^{4}$ Neste sentido, os estudos que tratam do turismo à procura de sexo protagonizado por mulheres dos países ricos são particularmente sugestivos: PHILLIPS, J oan L. Tourist oriented prostitution in Barbados: The Case of the Beach Boy and the While Female Tourist In: Kempadoo, Kamala e Doezema, Jo. Global sex workers, Rights, Resistance, and Redefinition. Londres, Routledge, 1998; DAHLES, Heide e BRAS, Karin. Entrepreneurs in Romance. Tourism in Indonésia. Annals of Tourism Research, vol. 26, n²2, 1999, pp.267-293; PrUITT, Deborah e LAFONT, Suzanne. For love and money. Romance Tourism in J amaica. Annals of Tourism Research, vol. 22, $\mathrm{n}^{\circ}$ 2, 1995, pp.422-440; MEISCH, Lynn. Gringas and Otavaleños, Changing Tourist Relations. Annals of Tourism Research, vol. 22, n² 2, 1995, pp.441-462.
} 
A discussão sobre as relações entre agentes situados nos dois lados (demanda e oferta) deste mercado e sobre sua própria organização remete, neste momento, a um aspecto particular: à intensificação da circulação através das fronteiras, com o objetivo de oferecer ou comprar serviços sexuais, um fenômeno que, na produção sobre o tema, é inserido na problemática da transnacionalização. Essa circulação é articulada à problemática considerada característica da "nova ordem global", uma ampliação na mobilidade (deslocamentos de massas de turistas, imigrantes, refugiados, exilados, trabalhadores) que afeta a política de e entre nações de uma maneira sem precedentes e, justaposta aos efeitos da mídia eletrônica, cria uma nova ordem de instabilidade na produção das subjetividades modernas. ${ }^{5}$

$\mathrm{Na}$ literatura feminista, o termo transnacional é utilizado de diversas maneiras. A idéia geral é que a noção alude a laços, vínculos, conexões entre grupos para além das fronteiras nacionais (que não privilegiam o papel do Estado) ${ }^{6}$. Mas, se em algumas aproximações a noção se refere basicamente à maneira como os migrantes criam e sustentam relações sociais, econômicas e culturais entre 0 lar e 0 contexto de migração ${ }^{7}$, em outras se afirma que compreender as conexões transnacionais exige olhar para além da interação entre países de origem e destinação,

\footnotetext{
${ }^{5}$ Appadural, Arjun. Modernity at large. Cultural Dimensions of Globalization. University of Minnesota Press, 1996.

${ }^{6}$ Aidoo, Ama Ata; Acosta-BelÉn, Edna; Basu, Amrita; CondÉ, Maryse; Painter, Nell; SaAdawi, Nawal El. Ama Ata Aidoo, Edna Acosta-Belén, Amrita Basu, Maryse Conde, Nell Painter and Nawal El Saadawi speak on feminism, race and transnationalism. Méridians: feminism, race, transnationalism, vol I, $n^{\circ} 1,2000, p p .1-28$.

7 Phizacklea, Annie. Gendered actors in migration. In: Andall, J acqueline. (ed.) Gender and Ethnicity in Contemporary Europe. Berg, Oxford, 2003.
} 
Gênero no mercado do sexo

considerando redes migratórias mais amplas. ${ }^{8}$ Nesta perspectiva se inserem autoras que consideram os processos transnacionais como processos de atravessar fronteiras nas quais os migrantes estabelecem relações complexas com diferentes locais e formam comunidades novas e diferentes. Isto inclui redes de migrantes e laços sociais, simbólicos e materiais entre homeland e destinação e relações entre destinações, conectando diversos espaços nacionais ${ }^{9}$. E este é, precisamente, o sentido que o termo adquire na literatura que trata do mercado sexual global. ${ }^{10}$

Ao vincular o mercado do sexo à transnacionalização, essas abordagens não ignoram a circulação através das fronteiras que, vinculada ao comércio do sexo, teve lugar no passado. As análises sobre as narrativas do tráfico de mulheres produzidas na última parte do século XIX e inícios do XX mostram a relevância a elas concedidas nesse período, com efeitos que se estenderam para além dele (este aspecto é destacado nos textos apresentados por Cristiana Schettini Pereira e Kamala Kempadoo, neste número). Contudo, as aproximações que analisam 0 período atual consideram a singularidade de um movimento de circulação que, fluindo através de redes transnacionais e em cuja constituição participam novos meios tecnológicos (como a mídia eletrônica), é percebido como tendo se intensificado nos últimos 20 ou 30 anos. ${ }^{11}$

As contribuições da histo riografia, através do distanciamento crítico com o passado que ela pode oferecer, são inestimáveis para pensar nessa singularidade e, ao mesmo tempo, nas analogias

${ }^{8}$ AnTHIAS, Floya e LAZARIDIS, Gabriela. Gender and Migration in Southern Europe, Women on the Move. Oxford, Berg, 2000.

${ }^{9}$ ANTHIAS, F. Metaphors of home: gendering new migrations to Southern Europe. In: ANTHIAS, Floya e LAZARIDIS, Gabriela. Gender... Op. cit.

${ }^{10}$ Ver THORBEK, Susanne \& PATtAnAIK, Bandana: Transnational prostitution. Changing global patterns. Zed Books, 2002.

${ }^{11}$ ThoRbek, S. Prostitution in a Global Context: Changing patterns. In: ID., IB. 
presentes na maneira como esses movimentos de pessoas têm sido tratados, no passado e no presente. Ao comparar os resultados de pesquisas sobre a construção de narrativas acerca do tráfico no passado ${ }^{12}$ e o debate atual, é possível estabelecer relações entre a intensa preocupação por essa problemática nas viradas dos séculos XIX e XX, dois momentos marcados, precisamente, pela profunda inquietação em relação à migração. Essas relações abarcam, também, a dimensão internacional dessas preocupações e do debate suscitado e seus efeitos na promulgação de leis. Nesse sentido, é importante observar que a discussão atual sobre o mercado do sexo, marcada por um interesse quase obsessivo com o tráfico de seres humanos com fins de exploração sexual, mostra o peso político da circulação das idéias através das fronteiras. Refiro-me às idéias sobre prostituição, sobre migração e sobre as relações entre ambas, que informam a promulgação de leis com diferentes graus de alcance.

Um ponto da maior importância e que torna o debate mais complexo é que se as legislações sobre prostituição são "nacionais", estamos frente a uma pressão internacional, exacerbada neste momento pelas discussões, medidas e articulações internacionais para reprimir o tráfico internacional de pessoas. $^{13} \mathrm{E}$ são particularmente complexas, porque, visando proteger potenciais vítimas, incidem diretamente no desempenho de atividades nos mercados do sexo nacionais, na migração e, de maneira específica, nas vidas de migrantes indocumentados "sem papéis". Estas questões são tratadas nos texto do G rupo DaVida,

${ }^{12}$ PereiRA, Cristiana Schettini. Fazer a vida na América do Sul: prostitutas e as histórias de tráfico de mulheres entre Rio de Janeiro e Buenos Aires. Projeto de pós-doutorado, 2003.

${ }^{13}$ Anderson, Bridget $\&$ O'CONnell Davidson, Julia. Trafficking, a demand - led problem? A multy-country pilot study. Part 1 "Review of evidence and debates", Save the Children, 2004. http://www.jagori.org/ research_dst.htm. 
Gênero no mercado do sexo

Kamala Kempadoo, Dolores Juliano, Laura Agustín, Gloria Patricia Díaz Barrero.

0 estudo dos diversos aspectos do mercado do sexo, considerado de relevância social (e, em certos âmbitos, de urgente solução, por suas eventuais implicações com 0 envolvimento de crianças e com a privação da liberdade de adultas/os) atrai a atenção do debate público e é objeto de uma produção diversificada que está longe de restringir-se às pesquisas acadêmicas. 0 artigo do grupo DaVida, neste número, oferece uma idéia dessa diversidade e dos problemas apresentados por parte dessa produção. Sem dúvida, se trata de uma área que ainda requer a realização de pesquisas possibilitando perceber a complexidade nela presente. Todavia, cabe perguntar (nesta e em outras temáticas consideradas de análoga importância e urgência social), como os estudos nela centradas contribuem para 0 avanço do conhecimento no âmbito das ciências sociais e, particularmente, do conhecimento em termos de gênero?

Refletir sobre esta questão exige considerar que os estudos sobre esta problemática tendem a estarem informados pelas diferentes posições feministas no debate sobre prostituição. Essas posições foram delineadas, sobretudo, na discussão internacional, conhecida como as batalhas do sexo (sex wars ${ }^{14}$ ), centrada na pornografia e na prostituição e se articularam com diferentes posturas em termos do estatuto legal que a prostituição deveria assumir (tais relações são consideradas nos textos de Dolores Juliano e Kamala Kempadoo). É importante perceber que as divisões presentes nesse debate são alimentadas não apenas pela maneira como diferentes correntes percebem a prostituição, mas, também, a sexualidade.

Longe de existir um acordo, o pensamento feminista apresenta diferenças significativas no que se refere ao significado

\footnotetext{
${ }^{14}$ Ver Friedman, Estelle e THORNE, Barrie. Introducction to the Feminist Sexuality Debates. Signs, vol. 10, n 11,1984, pp.102-135.
} 
concedido à sexualidade. De acordo com Wendy Chapkis ${ }^{15}$, a oposição entre duas visões antagônicas sobre a sexualidade, presente já nas primeiras discussões das sufragistas, marca essas divergências. Alguns grupos entendiam a sexualidade como o elemento utilizado para objetificar as mulheres, impedindo-as, portanto de aceder ao reconhecimento de sujeitos portadores de direitos civis. Ao contrário, outros grupos entendiam a sexualidade como uma arena de potencial liberação para as mulheres. Segundo a autora, essas diferenças, atualizadas no marco da segunda onda do feminismo, essas diferenças teriam tido o efeito da criação de dois campos dicotômicos descritos, de maneira simplista, um como hostil ao sexo, que era percebido como a fonte da opressão feminina em uma ordem patriarcal e outro que defendia o sexo como fonte de prazer e poder nas vidas das mulheres.

Os debates sobre os significados e a função do sexo foram mais complexos, mas a questão é que no âmbito deles, a pornografia e a prostituição operaram como um ponto central, como um divisor de águas. De acordo com Chapkis, nessas discussões a prostituta ocupou tanto o lugar da escrava sexual como o do agente mais subversivo dentro de uma ordem social sexista. As percepções so bre a prostituição em um e outro extremo são diversificadas. Num deles, a vinculação das mulheres com 0 sexo é percebida como a raiz de sua opressão e abuso. Assim, a prostituição é vista como caso extremo do exercício abusivo do sexo, portanto, quem oferece serviços sexuais é percebida como inerentemente vítima de violência. Nessa visão, a prostituta é um objeto sexual, um ser passivo e carente de poder.

No outro pólo, há posições que, ao contrário, consideram a vinculação das mulheres com o sexo a fonte de seu maior poder. Assim, a prostituta seria um símbolo da autonomia sexual das mulheres e, como tal, uma ameaça potencial ao controle patriarcal

${ }^{15}$ Ver CHAPKIS, Wendy. Live Sex Acts. Women performing erotic labour. Londres, Cassell, 1997. 
Gênero no mercado do sexo

sobre a sexualidade das mulheres. Outras, mais cautelosas, pensam no sexo como um terreno de disputa, não como um campo fixo de posições de gênero e poder. Estas linhas de pensamento reconhecem a existência de uma ordem sexista, mas consideram que ela não é inteiramente determinante. 0 sexo é visto como uma tática cultural que pode tanto desestabilizar o poder masculino como reforçá-lo. As práticas de prostituição, tais como outra forma de mercantilização e consumo, devem ser lidas de maneiras mais complexas que apenas uma confirmação da dominação masculina: em certas circunstâncias, elas podem ser espaços de resistência e de subversão cultural. Por este motivo, estas linhas consideram que a posição da prostituta não pode ser reduzida à de um objeto passivo utilizado na prática sexual masculina, mas como um espaço de agência no qual se faz um uso ativo da ordem sexual existente.

De acordo com autoras que participam no debate, em uma observação que compartilho, umas e outras imagens da prostituta devem ser consideradas tipos ideais que povoam a retórica feminista, uma vez que as realidades das inserções no mercado do sexo são infinitamente mais variadas. No entanto, estas idéias são importantes para compreender as aproximações presentes nos estudos sobre o mercado do sexo. No âmbito da produção acadêmica, essas divisões são visíveis. Mas, ao lado de uma produção que condena o trabalho sexual, nas últimas décadas é possível detectar novos olhares sobre esse tipo de serviços.

Acompanhar essas discussões sugere que a inovação presente em algumas linhas do debate atual reside, sobretudo, em um deslocamento do posicionamento das pessoas que prestam serviços sexuais. São linhas de produção acadêmica que se desenvolveram trabalhando em estreita colaboração com as idéias de trabalhadores do sexo, entre os/as quais se dissemina a exigência de serem considerados sujeitos de direitos enquanto integrantes de uma categoria ocupacional. O deslocamento se reflete em perspectivas que, longe de considerar as/os trabalhadores do sexo vilões/ãs ou vítimas, concedem a eles 
um lugar de seres dotados de capacidade de agência. Esse movimento, intimamente vinculado à interação entre prestadoras/es de serviços sexuais/ativistas e acadêmicos, é perceptível na organização de coletâneas nas quais esses diversos agentes escrevem conjuntamente ${ }^{16}$ e no conteúdo dos textos nelas publicados. Na literatura acadêmica, esse deslocamento exige uma revisão dos pressupostos que orientaram as reflexões e pesquisas sobre prostituição.

Ao longo da década de 1980 os grupos de trabalhadoras/es do sexo se difundiram em diversas partes do mundo ${ }^{17} \mathrm{e}$, em mediados dessa década, tiveram lugar os dois primeiros congressos mundiais de prostitutas, em Amsterdam e Bruxelas. ${ }^{18}$ Ao longo desse processo, certos setores da academia foram aproximando-se destes movimentos, apoiando as idéias que deles surgiam. Os efeitos da interação entre algumas pessoas inseridas na academia e as integrantes dessas organizações são perceptíveis em publicações desse período ${ }^{19}$. No entanto, é ao longo da década de 1990 que os resultados desse diálogo se tornam mais visíveis.

Em 1993 Anne McKlintock, uma autora que se tornou mais conhecida por seus estudos sobre as relações entre gênero, raça e classe na formação do imperialismo britânico ${ }^{20}$, organizou uma seção especial do periódico acadêmico estadounidense Social

\footnotetext{
${ }^{16}$ MCKLINTOCK, Anne. Sex Workers and Sex Work. Social Text, n 37. A Special Section Edited by Anne McKlintock Explores the Sex Trade, Winter, 1993; KEMPADO0, K. e DOEZEMA, J. G lobal sex workers... Op. cit.

${ }^{17}$ No Brasil, o grupo DaVida foi fundado, no Rio de Janeiro, em 1987.

${ }^{18}$ ChAPKIS, Wendy. Live Sex Acts... Op. cit.; McKlinTock, A. Sex Workers... Op. cit.

${ }^{19}$ Pheterson, Gail. The whore stigma: Female deshonor and male unworthiness. The Hague. Ministry of Social Affairs and Employment, 1986.

${ }^{20}$ MCKLINTOCK, A. Imperial leather. Londres, Routledge, 1995, Intoduction, pp.1-18.
} 
Gênero no mercado do sexo

Text inteiramente dedicada ao comércio sexual ${ }^{21}$. Ao apresentar a seção, a autora chama a atenção para a transgressão presente na inclusão de ensaios escritos por trabalhadoras do sexo em um periódico acadêmico. Esse procedimento, que concede a essas mulheres o estatuto de agentes, é considerado uma ação política radical, pois toma como pressuposto a legitimidade das ações das prostitutas. Os textos publicados nesse periódico, engajando-se em discussões sobre as políticas da agency, da representação e do estabelecimento de alianças, contestam frontalmente 0 estigma vinculado à prostituição, inclusive nas abordagens feministas. Esses artigos afirmam a validade do trabalho sexual como intercâmbio de serviços específicos por dinheiro que deveria gozar de respeito análogo ao concedido a outras ocupações do setor de serviços.

Essas abordagens são re-criadas e alargadas em outra coletânea marcante, publicada em finais da década de 1990: Global Sex Workers, organizada por Kamala Kempadoo, uma acadêmica e por Jô Doezema ${ }^{22}$ que, neste livro, se apresenta como uma trabalhadora sexual. Os textos que integram a coletânea aprofundam questões relacionadas à conceitualização do trabalho sexual e aos aspectos legais vinculados ao exercício do mesmo, mas o fazem com particular atenção no posicionamento das trabalhadoras do sexo dos países do "Terceiro Mundo" no mercado transnacional do sexo em um mundo globalizado. Considerando esse posicionamento, os textos chamam a atenção para o racismo presente nas estruturas e desejos que organizam indústrias locais específicas e ao imperialismo cultural evidente nos discursos internacionais sobre prostituição, incluindo aqui certas abordagens feministas. $E$, situando-se no marco do pensamento feminista, as autoras contestam as abordagens, também feministas, que percebem as trabalhadoras do sexo como inerentemente vítimas (passivas) da

\footnotetext{
${ }^{21}$ MCKLINTOCK, A. Sex Workers... Op. cit.

${ }^{22}$ KempadoO, K. e Doezema, J. G lobal sex workers... Op. cit.
} 
violência sexual. Ambas publicações são significativas em termos de expressar aspectos importantes dos novos olhares sobre o trabalho sexual. ${ }^{23}$

Esse breve percurso sobre as relações entre perspectivas feministas e a produção sobre trabalho sexual possibilita perceber discrepâncias no que se refere ao lugar que a sexualidade tem no posicionamento social das mulheres envolvidas com esse tipo de serviço, mas, também, em termos da maneira como operam as relações de poder. Neste sentido, é necessário observar que essa produção não apresenta acordos sobre as relações entre estrutura e agência, entre a determinação (absoluta ou relativa) de fatores estruturais e os graus de possibilidade de ação dos agentes sociais. $E$, se em muitos desses trabalhos o foco está centrado nas mulheres no mercado como prestadoras de serviços, as novas discussões tornam mais complexas as relações entre determinações estruturais, agência e gênero ao contemplar a participação das mulheres no mercado do sexo como empresárias ou, situadas no lado da demanda, como consumidoras (aspectos tratados pelos textos de Elisiane Passini e Laura Agustín) e de homens e transgêneros no lado da oferta de serviços sexuais (este último aspecto é tratado no texto de Larissa Pelucio).

Parte da produção sobre prostituição apresenta a categoria gênero como uma diferenciação linear e quase fixa. Este é um aspecto que, longe de restringir-se aos estudos sobre essa problemática, perpassa a literatura sócio-antropológica sobre gênero e sexualidade. Nessa produção, que está longe de apresentar acordos no que se refere à delimitação da sexualidade, gênero é tratado de diferentes maneiras. Essa diversidade mantêm

\footnotetext{
${ }^{23}$ Para um mapeamento alternativo dos textos significativos na área ver: SHAH, Svati P. Prostitution, Sex Work and Violence: Discursive and Political Contexts for Five Texts on Paid Sex, 1987-2001. In: D'CRuzE, Shani e RAO, Anupama. Violence, Vulnerability and Embodiment Blackwell, 2005.
} 
Gênero no mercado do sexo

relações com os marcos conceituais utilizados e com as dimensões privilegiadas na análise dessa categoria.

Em primeiro lugar, gênero pode ser considerado na perspectiva dos papéis sexuais, e/ou da distinção sexo/gênero ou em leituras que contestam essa distinção. Ao mesmo tempo, essa categoria pode ser pensada privilegiando as dimensões representacionais, ou o plano das identidades, isto é, à maneira como se constitui o sentimento individual ou coletivo de identidade $e^{24}$. Por outra parte, e talvez seja esse um dos pontos mais significativos, não há convergências em termos de tratar sexualidade e gênero como analiticamente distintos e, portanto, não há convergências sobre as possíveis relações entre ambos. ${ }^{25}$

Certas linhas feministas, refletindo sobre a subordinação das mulheres, particularmente as que desenvolvem uma crítica à prostituição e à pornografia, acabam confundindo, num raciocínio circular, sexualidade e gênero. Refiro-me especificamente a Catherine MacKinnon, que pensa a sexualidade como uma forma de poder, corporificada por gênero. Segundo a autora, a heterossexualidade institucionalizaria a dominação sexual masculina e a submissão feminina. ${ }^{26}$ Outras, ao contrário, foram pioneiras no questionamento à relação direta e naturalizada entre reprodução e gênero, um de cujos efeitos é confundir sexualidade

${ }^{24}$ GrossI, Miriam Pillar. Identidade de gênero e sexualidade. Antropologia em Primeira Mão, s/d, Universidade Federal de Santa Catarina, PPGAS.

${ }^{25}$ VANCE, Carol. A antropologia redescobre a sexualidade: um comentário teórico. PHYSIS, Revista de Saúde Coletiva, vol. 5, no 1, 1995, p.13.

${ }^{26}$ Ver: MACKINNON, Catherine. Marxism, feminism and the State: Toward Feminist J urisprudence. Signs 7 (5), 1982, pp.515:544 e DWORKIN, Andrea. Against the Male Flood. In: Cornell, Drucilla. Feminism and Pornography. 2000; GREGORI, Maria Filomena: Prazer e perigo: notas sobre feminismo, sex-shops e S/M. In: PISCITELLI, A. et alii. (orgs.) Sexualidade e Saberes, Convenções e Fronteiras. Rio de Janeiro, Garamond, 2004 
e gênero. Ao desenvolver a idéia de sistema de sexo e gênero, Gayle Rubin realizou um trabalho pioneiro mostrando como essa relação perpassa importantes marcos analíticos das ciências sociais (entre eles, as formulações levistraussianas). As reflexões dessa autora mostram, também, como essa relação está ancorada num pressuposto que tende a aparecer de maneira mais velada: aquele que naturaliza a heterossexualidade. ${ }^{27}$

$\mathrm{Na}$ atualidade, são, sobretudo, algumas linhas inseridas nos estudos queer as que, enfatizando incisivamente a distinção entre sexualidade não reprodutiva e reprodutiva (assinalando, aliás, que esta última ocupa um pequeno espaço no vasto campo da sexualidade), insistem veementemente na distinção analítica entre gênero e sexualidade - isto é, se em contextos específicos sexualidade e gênero se inter-relacionam, não são o mesmo. ${ }^{28} E$, neste aspecto, 0 trabalho de Rubin é novamente pioneiro, mostrando como a complexidade de distinções entre características consideradas femininas e masculinas atravessam diversas modalidades e estilos de práticas da sexualidade. ${ }^{29}$

A distinção analítica entre gênero e sexualidade não se restringe aos estudos queer. Mas, nas análises de sexualidades heterossexuais, gênero aparece freqüentemente aprisionado numa distinção binária na qual a sexualidade é atravessada por uma linha divisória entre homens e mulheres que parece estabelecer uma continuidade entre "sexo" e gênero. Talvez o caráter redutor,

\footnotetext{
${ }^{27}$ RUBin, Gayle. The Traffic in Women. Notes on the "Political Economy" of Sex". In: Reiter, Rayna. (ed.) Toward an Anthropology of Women. New York, Monthly Review Press, 1975.

${ }^{28}$ RubiN, G. Thinking Sex: Notes for a Radical Theory of the Politics of Sexuality. In: Abelove, BaRALE \& H ALPERIN. The lesbian and gay studies reader. Londres, Routledge, 1992 [1984].

29 "Sexual Traffic". Interview - Gayle Rubin with J udith Butler [tradução em cadernos pagu (21), 2003] e BUTLER, Judith. Against proper objects. In: WeEd, Elizabeth and SCHOR, Naomi. Feminism meets queer theory. Brown University, 1997.
} 
Gênero no mercado do sexo

em termos de uma análise de gênero, de parte dessa produção que trabalha com heterossexualidades resida no fato de tomar como foco e/ou ponto de partida a idéia (implícita) da existência de identidades de gênero coerentes e estáveis - e essa idéia dificilmente se desvincula da construção do gênero em função do papel desempenhado por homens e mulheres na reprodução biológica. Alguns estudos operam com a idéia de uma identidade, às vezes implícita, e relativamente fixa de gênero, que transcende classes sociais e, ocasionalmente, inclusive culturas e/ou nacionalidades, e cuja fixidez chama a atenção levando em conta as distinções realizadas no que se refere ao peso (diferencial) da sexualidade na constituição da subjetividade. Por outro lado, as linhas que pensam as identidades como fluidas, à maneira das performativistas, apresentam outras dificuldades. Essas abordagens dificilmente oferecem acesso aos "scripts" que, contextualizadamente, estão sendo "performados".

Os efeitos desses problemas, perceptíveis nas análises sobre sexualidade, são particularmente evidentes em estudos sobre prostituição, sobretudo, nas linhas que aderem às leituras ("antisexo") das quais Catherine MacKinnon e Andréa Dworkin oferecem exemplos, mas não se restringem a elas. As aproximações desenvolvidas nas novas leituras sobre o trabalho sexual, contudo, vem oferecendo contribuições que desestabilizam essa linearidade, tornando mais complexas as leituras sobre alocações de características consideradas femininas e masculinas e das relações desiguais de poder que permeiam nichos específicos do mercado do sexo. Um exemplo sugestivo é oferecido pela análise do sexo comercial no âmbito do sado-masoquismo realizado por Anne MacKlintock. ${ }^{30}$

$\mathrm{H}$ istoricizando o sado-masoquismo (que, segundo a autora, surgiu no final do século XVIII, na Europa, como sub-cultura histórica, emergindo junto com a llustração imperial), MacKlintock

\footnotetext{
${ }^{30}$ MaCKLINTOCK, Anne. Maid to Order, Commercial fetishism and gender power Social text, 1993.
} 
argumenta que essa modalidade de comércio de sexo está marcado pela economia da conversão. De acordo com ela, o serviço pago com mais freqüência por homens, no $S / M$ heterossexual, é a submissão. A autora considera que, nesse âmbito, os papéis são trocados, de uma maneira teatral e ritualizada em um jogo no qual se altera a relação linear entre homens= poder e mulheres= submissão. Assim, este tipo de troca, que toma emprestados toda a parafernália e símbolos das culturas cotidianas do poder, parecendo aludir a eles da maneira mais ortodoxa, através do exagero, expressaria esse poder como se fosse aberto à mudança. Esta modalidade de troca de sexo por dinheiro representaria hierarquia, diferença e poder, e os reverteria, transmutando os significados sociais que toma emprestados.

Segundo Macklintock, os limites de gênero e classe aparecem aqui abertos à invenção e transfiguração. Contudo, o contexto nunca desaparece: ele oferece os elementos a serem encenados e revertidos e a ele se retorna novamente. Aliás, Macklintock utiliza o exemplo do S/M para afirmar que traz a um limite conceitual à promessa libertária de que a agência individual é suficiente para resolver os dilemas sociais. Em sua interpretação do sexo, o contexto social e político, para além do indivíduo, são de crucial importância. Segundo a autora, mesmo dentro do marco do dinheiro e da fantasia controlados do sado-masoquismo comercial, os homens entregam o poder às mulheres apenas temporariamente, mantendo o controle fora desse marco limitado; as contradições podem ser negociadas mas não necessitar ser resolvidas, porque a fonte desses paradoxos estão além do individual.

Detive-me nesta análise porque ela oferece um exemplo de leituras possíveis, em termos de gênero e poder, que, sem ignorar as constrições produzidas pelos códigos de gênero, não reduzem linearmente as interações sexuais comerciais à idéia de submissão feminina/dominação masculina. Nesse sentido os estudos aqui apresentados, ao mostrar deslocamentos nos lugares 
Gênero no mercado do sexo

"tradicionalmente" alocados aos/às agentes no mercado do sexo e embaralhar as noções de masculinidade e feminilidade presentes nos critérios de atração erótica, com destaque para ambigüidade corporificada pelos transgêneros, oferecem significativas contribuições para considerar, a partir de diferentes ângulos, as relações entre gênero, poder e sexualidade no mercado global do sexo contemporâneo.

Considerar a oferta e demanda de serviços sexuais/sensuais no mercado transnacional do sexo remete, necessariamente, a considerar como convenções corporais e códigos de gênero são produzidos no marco das desigualdades que permeiam as relações entre os países do Norte e do Sul. Categorias de gênero, "raça", nacionalidade, região, idade se intersectam, articuladas, construindo-se umas através das outras ${ }^{31}$, em processos de erotização e também de viabilização de consumo erótico. Estes aspectos são tratados nos textos de Patricia Diaz, Adriana Piscitelli e Marta Savigliano. A erótica da diferença cultural, (termos que tomo emprestados dessa última autora), remete a um aspecto relevante que se delineia em seu artigo e no de Silva e Blanchette. Os processos de exotismo nos quais a cultura possibilita aludir à diferença, deixando de lado a desigualdade, permeiam as relações Norte e Sul e a mercantilização de lugares e regiões, de seus habitantes e sua produção cultural, inclusive a arte. Mas, como traçar uma linha de demarcação entre as conceitualizações que, produzidas no âmbito desses processos, atravessam essas relações em sentido amplo e aquelas acionadas pelos/as consumidores/as de sexo comercial?

Encerrando esta apresentação, chamo a atenção para a singularidade do documento publicado neste número dos cadernos pagu, no qual Dora Barrancos comenta registros

\footnotetext{
${ }^{31}$ Para uma discussão (feminista) sobre categorias de articulação ver BRAH, Avtar. Cartographies of diaspora, constesting identities. Londres, Routledge, 1996 e para uma análise utilizando essa noção ver MACKLINTOCK, A. Imperial Leather... Op. cit.
} 
Adriana Piscitelli

fotográficos do cotidiano em um bordel argentino, na década de 1940. Finalmente, observo que vários dos textos aqui publicados foram apresentados no Simpósio Género y Transnacionalización (Primer Congreso Latinoamericano de Antropologia, Rosário, julho de 2005), organizado por Monica Tarducci e por mim. Registro meu agradecimento a Monica e aos participantes do Simpósio, cujos comentários informaram a elaboração final desses artigos e as reflexões aqui esboçadas.

Adriana Piscitelli 